\title{
EL TEDH Y LAS CONDENAS A ESPAÑA POR LA VULNERACIÓN DEL DERECHO A SER JUZGADO EN UN PLAZO RAZONABLE: LAS DIFICULTADES PARA ALCANZAR UNA DURACIÓN ÓPTIMA DE LOS PROCESOS JUDICIALES ${ }^{1}$
}

\author{
LUIS E. DELGADO DEL RINCÓN \\ Profesor Titular de Derecho Constitucional \\ Universidad de Burgos
}

SUMARIO

I. Introducción. II. Los criterios utilizados por el TEDH para determinar la vulneración del derecho a ser juzgado en un plazo razonable: una aproximación al estándar mínimo de protección. III. Las condenas a España por la violación del derecho a ser juzgado en un plazo razonable. IV. Sobre medidas y remedios que eviten futuras condenas al Estado español por la vulneración del derecho a ser juzgado en un plazo razonable.

\section{INTRODUCCIÓN}

El derecho a que una causa sea juzgada en un plazo razonable y sin dilaciones indebidas es un derecho que no solo conlleva una obligación de los poderes públicos de organizar el sistema judicial para que los justiciables obtengan una resolución judicial en un tiempo prudencial, sino que constituye también una garantía de un derecho fundamental, el derecho al proceso debido o a la tutela judicial efectiva. Se trata de un derecho que, desde hace décadas, está regulado en diferentes textos jurídicos internacionales y estatales. En el ámbito europeo, puede destacarse, en el seno del Consejo de Europa, el Convenio Europeo para la Protección de los Derechos Humanos y de las Libertades Fundamentales (CEDH), adoptado por el Consejo de Europa el 4 de noviembre de 1950, que proclama en su art. 6.1 que «toda persona tiene derecho a que su causa sea oída (...)

1 Este trabajo se realiza en el marco del Proyecto de Investigación DER2016-75993-P, sobre «España ante Europa: retos nacionales en materia de derechos humanos» (2017-2020), del Ministerio de Economía, Industria y Competitividad. 
dentro de un plazo razonable». En el marco del Derecho de la Unión Europea, ha de citarse la Carta de los Derechos Fundamentales de la Unión Europea (CDFUE), de 7 de diciembre de 2000, en su versión adaptada tras la entrada en vigor del Tratado de Lisboa de 13 de diciembre de 2007, que lo reconoce en su art. 47 en términos idénticos a los del art. 6.1 CEDH. Estamos ante normas jurídicas que contienen un derecho y una obligación cuyo objeto es impedir que se haga realidad en el foro judicial la máxima de que «nada se parece tanto a la injusticia como la justicia tardía».

La Constitución proclama en el art. 24.2, el derecho de todas las personas «a un proceso público sin dilaciones indebidas $»^{2}$. Relacionado estrechamente con este derecho fundamental, otro precepto, el art. 121 CE prevé también un derecho constitucional de configuración legal no tutelable en amparo, el derecho a una indemnización por los daños causados por error judicial y funcionamiento anormal de la Administración de Justicia. El legislador ha desarrollado el contenido del art. $121 \mathrm{CE}$ y ha regulado el derecho a la indemnización por los daños causados por las dilaciones indebidas, como una manifestación del funcionamiento anormal de la Administración de Justicia, en el art. 292 y ss. de la Ley Orgánica del Poder Judicial (LOPJ). De hecho, la concesión de una indemnización por haber padecido dilaciones indebidas en un proceso es una forma de reparación de la vulneración del derecho a un proceso sin dilaciones indebidas del art. 24.2 CE, cuando este derecho no ha podido ser reparado in natura ${ }^{3}$.

Aunque el derecho del art. 24.2 CE persiga el mismo fin que el derecho a ser juzgado en un plazo razonable del art. 6.1 CEDH, que el proceso judicial en el que intervienen las partes se resuelva lo antes posible, ambos derechos difieren en el procedimiento seguido para su restablecimiento. Así, en el caso de vulneración del derecho del art. 6.1 $\mathrm{CEDH}$, el TEDH no declara la reparación in natura, sino que obliga al Estado a indemnizar económicamente al ciudadano por los daños morales causados (no los materiales) y a que adopte las medidas oportunas para evitar que se viole nuevamente. El TEDH lo que hace es juzgar a los Estados, comprobar si el periodo de tiempo invertido en la tramitación de los procesos judiciales es o no excesivo y, en caso de serlo, les conmina a que adopten las medidas necesarias para respetar el derecho a ser juzgado en un plazo razonable ${ }^{4}$.

2 Aun cuando algunas decisiones constitucionales han considerado al derecho a un proceso sin dilaciones indebidas del art. 24.2 CE como una garantía procesal e instrumental del derecho a la tutela judicial efectiva del art. 24.1 CE (SSTC 24/1981, de 14 de julio, FFJJ 3 y 4 y 49/1991, de 11 de marzo, FJ 3); el Tribunal Constitucional ha consolidado como doctrina que los derechos del art. 24.1 y 2 CE son derechos fundamentales autónomos, diferenciados y con sustantividad propia, susceptibles, por tanto, de ser vulnerados por causas diferentes Cfr., entre otras, las SSTC 26/1983, de 13 de abril, FJ 2; 36/1984, de 14 de marzo; 133/1988, de 4 de julio; 10/1991, de 17 de enero; 179/1993, de 31 de mayo; 180/1996, de 17 de diciembre y 125/1999, de 30 de julio.

$3 \mathrm{El} \mathrm{TC}$, en los casos en los que ha estimado la lesión del derecho a un proceso sin dilaciones indebidas del art. 24.2 CE, ha precisado que solamente puede limitarse en el fallo (con arreglo a lo dispuesto en los arts. 54, 55 y 58 LOTC) a pronunciarse sobre la declaración de la existencia del derecho de indemnización, sin que, de ninguna manera, pueda procederse a determinar su cuantía o a otorgarla, remitiendo al particular interesado, para hacer efectiva la reclamación de la indemnización, a los cauces previstos legalmente en el art. 293.2 LOPJ. Esta doctrina jurisprudencial se recoge, entre otras, en las SSTC 139/1990, de 23 de octubre, FJ 2; 180/1996, de 17 de diciembre, FJ 7; STC 33/1997, de 24 de febrero FJ 3; 99/1998, 9 de junio FJ 1 y 125/1999, de 30 de julio, FJ 2.

4 Cfr. Ortega Carballo, C., «Soto Sánchez c. España (STEDH de 25 de noviembre de 2003): el derecho a un proceso judicial sin dilaciones indebidas», En Conflicto y diálogo con Europa. Las condenas a España del Tribunal Europeo de Derechos Humanos, R. Alcácer Guirao, M. Beladiez Rojo y J.M. Sánchez Tomás (coord.) Civitas Thomson Reuters, Navarra, 2013, p. 230, sobre lo manifestado por el TEDH en las SSTEDH Frydlender c. Francia, de 27 de junio de 2000 y $A A V$ c. Francia, de 19 de junio de 2001. Vid. también este autor, ob. cit., pp. 229-238, sobre algunos de 
El TEDH y el TC han realizado una interpretación extensiva de los derechos del art. 6.1 CEDH y del art. 24.2 CE, reconociendo que aunque, en un primer momento, pudiera entenderse que los derechos solo eran invocables y aplicables en el proceso penal, por las consecuencias que las dilaciones indebidas tienen sobre la libertad personal del justiciable, que puede hallarse privado de ella de forma provisional o definitiva, posteriormente ampliarán su aplicación a los procesos de cualquier orden jurisdiccional: civil, contencioso-administrativo, laboral o militar, cualquiera que sea la fase en que se encuentren, preparatoria o en ejecución de sentencia judicial. También los aplicarán a los procesos de la jurisdicción constitucional.

En el ámbito de la jurisdicción de la Unión Europea, el Tribunal de Justicia (TJUE) ha interpretado y aplicado el derecho a ser juzgado en un plazo razonable del art. 47 CDFUE, cuando este ha sido vulnerado por retrasos injustificados de los órganos judiciales de la Unión Europea (el Tribunal de Justicia y el Tribunal General), acudiendo a los criterios fijados por la jurisprudencia del TEDH sobre el derecho del art. 6.1 $\mathrm{CEDH}^{5}$. La vulneración del derecho del art. $47 \mathrm{CDFUE}$ es considerada como una violación suficientemente caracterizada del Derecho de la Unión Europea. Ha de tenerse presente que cuando se ratifique el CEDH por la Unión Europea, con el sometimiento directo y expreso a la jurisdicción del TEDH, este órgano garantizará en última instancia la tutela del derecho a ser juzgado en un plazo razonable, en todas las actuaciones judiciales que se lleven a cabo por los órganos judiciales de la Unión Europea $^{6}$.

los elementos y trámites que diferencian los procedimientos seguidos ante el TEDH y el Tribunal Constitucional para la reparación y restablecimiento del derecho lesionado; así como SALAdo OsunA, A. «El «plazo razonable» en la administración de justicia: una exigencia del Convenio Europeo de Derechos Humanos», en García Roca, J. y Santolaya Machetti, P. (coords.), La Europa de los Derechos. El Convenio Europeo de Derechos Humanos, CEPC, Madrid, 2009, pp. 305-308 y 317-321.

5 El Tribunal de Luxemburgo, en la STJUE Mabrouk. c. Consejo de la Unión Europea, de 5 de octubre de 2017, parágrafo 71 , reconoce, en este sentido, que «a la luz de la jurisprudencia del TEDH, el respeto del derecho a ser enjuiciado en un plazo razonable, como lo consagra el Derecho internacional, debe examinarse a la vista de las circunstancias del caso concreto, que exigen que se realice una valoración global, en particular a partir de criterios asociados a la complejidad del asunto y al comportamiento del demandante y de las autoridades competentes (véase TEDH, sentencia de 28 de junio de 2016, O'Neill y Lauchlan c. Reino Unido, ap. 86 y jurisprudencia citada). El examen del respeto del derecho a ser enjuiciado en un plazo razonable, tal como lo consagra el artículo 47 de la Carta, está regido por principios análogos en la jurisprudencia de los tribunales de la Unión (véase, en este sentido, la sentencia de 26 de noviembre de 2013, Groupe Gascogne/Comisión, ap.s 85 y 86 y jurisprudencia citada». Asimismo, en esta resolución, Groupe Gascogne c. la Comisión, de 26 de noviembre de 2013, parágrafo 86, se puntualiza por el TJUE que «la lista de los criterios pertinentes no es exhaustiva y la apreciación del carácter razonable de esa duración no exige un examen sistemático de las circunstancias del asunto en función de cada uno de ellos cuando la duración del proceso se revela justificada en función de uno solo. Así, la complejidad del asunto o un comportamiento dilatorio del recurrente pueden tenerse en cuenta para justificar un plazo a primera vista demasiado largo (véanse, en particular, la sentencia Der Grüne Punkt - Duales System Deutschland/Comisión, antes citada, parágrafo 182 y la jurisprudencia citada). En general, sobre la evolución de la jurisprudencia del TJUE en relación con la reparación del derecho fundamental a ser oído en un plazo razonable cuando ha sido vulnerado por los tribunales de la Unión Europea, vid. los trabajos de Cobreros Mendazona, E., «Violación del plazo razonable en el Tribunal de Justicia de la Unión Europea: su compensación y dos consecuencias importantes», Revista Vasca de Administración Pública, núm. especial 99-100, mayo-diciembre, 2014, pp. 921 y ss. y «La reparación del incumplimiento del plazo razonable en el Tribunal de Justicia de la Unión Europea y una posible consecuencia para el estatus de los derechos fundamentales», RVAP, n. ${ }^{\circ} 109-\mathrm{I}, 2017$, pp. 21 y ss.V

6 Cfr. Cobreros Mendazona, E., «La reparación del incumplimiento del plazo razonable...», ob. cit., p. 56. 


\section{LOS CRITERIOS UTILIZADOS POR EL TEDH \\ PARA DETERMINAR LA VULNERACIÓN \\ DEL DERECHO A SER JUZGADO EN UN PLAZO RAZONABLE: UNA APROXIMACIÓN AL ESTÁNDAR MÍNIMO DE PROTECCIÓN}

De acuerdo con una jurisprudencia ya consolidada, el TEDH ha establecido unos criterios objetivos para valorar si se ha vulnerado o no el derecho a ser juzgado en un plazo razonable del art. 6.1 CEDH. Mediante ellos el Tribunal examina en cada caso concreto si el proceso se ha tramitado dentro de un periodo de tiempo razonable, esto es, si han existido o no retrasos en la causa y, en caso de haberlos, si estos están justificados o no. En definitiva, el TEDH trata de concretar en cada caso el concepto jurídico indeterminado del «plazo razonable» y determinar si se ha conculcado o no el derecho del art. 6.1 CEDH.

Aunque no constituyan una lista cerrada, los criterios objetivos fijados por el TEDH son los siguientes:

1. la complejidad del litigio o asunto;

2. ${ }^{\circ}$ el comportamiento del demandante y

$3 .^{\circ}$ la conducta de las autoridades nacionales.

Según las circunstancias del caso concreto, el Tribunal utiliza también ocasionalmente un cuarto criterio, el del interés que el demandante arriesga en el litigio o las consecuencias que el retraso puede ocasionar en la esfera personal y patrimonial del demandante. Por regla general, el TEDH utiliza estos criterios conjuntamente para valorar la duración total del proceso en todos sus procedimientos y fases, sin perjuicio de que en algunos casos los aplique a uno de los procedimientos o a una de sus fases. Aunque el Tribunal se sirve de todos ellos para examinar la duración del proceso haciendo una valoración conjunta, en ocasiones, uno de ellos es el que resulta determinante o decisivo para declarar que el proceso se ha excedido del «plazo razonable».

1. Por lo que se refiere al criterio de la complejidad del litigio o asunto, el TEDH examina si han concurrido en el caso determinadas circunstancias relacionadas con elementos fácticos o jurídicos que han dificultado la tramitación y resolución de la causa, hasta el punto de impedir que pueda concluir en un «plazo razonable». En este sentido, el TEDH ha valorado la complejidad del asunto cuando han acontecido circunstancias de carácter fáctico como la implicación de varias personas en los hechos y la intervención de diversos tribunales ${ }^{7}$, el interés nacional de $\operatorname{los}_{\text {hechos }}{ }^{8}$ y la naturaleza del litigio por versar sobre asuntos complicados como la determinación de la propiedad de un bien inmueble , o la comisión de un delito de tráfico de drogas con una dimensión internacional ${ }^{10}$, o el enjuiciamiento de varios delitos ${ }^{11}$. La

7 SSTEDH Neumeister c. Austria, de 27 de junio de 1968; Billi c. Italia, de 26 de febrero de 1993; Djaid c. Francia, de 29 de diciembre de 1999; S.H.K. c. Bulgaria, de 32 de enero de 2004 y Salmanovov. Rusia, de 31 de octubre de 2010.

8 STEDH Dobbertin c. Francia, de 25 de febrero de 1993.

9 STEDH Hadjikostova c. Bulgaria, de 4 de marzo de 2004.

10 STEDH Djaid c. Francia, de 29 de diciembre de 1999 y Soto Sánchez c. España, de 25 de febrero de 2004

11 STEDH Dfehmi Koçc. Turquía, de 27 de junio de 2007. 
complejidad puede venir determinada también por cuestiones jurídicas sustantivas o procesales como la dificultad de encontrar determinados testigos ${ }^{12}$, la práctica de trámites complejos como las comisiones rogatorias ${ }^{13}$, la multiplicidad de incidentes procesales promovidos por las partes ${ }^{14} \mathrm{y}$ la sustanciación de cuestiones jurídicas difíciles y/o novedosas ${ }^{15}$.

2. $\quad$ El comportamiento del demandante puede influir también en la producción de los retrasos cuando este ha realizado actuaciones obstruccionistas o maniobras dilatorias para el proceso. Son situaciones que por la falta de diligencia del litigante pueden ser valoradas por el TEDH para como determinantes en la duración excesiva de un proceso $^{16}$. Ahora bien, en descargo de la conducta del demandante y, por regla general, en los procesos penales en los que ha intervenido como acusado o condenado, el TEDH ha reconocido que el art. 6.1 CEDH no exige a los interesados una cooperación activa con las autoridades judiciales. De ahí que el ejercicio legítimo por el demandante de todos los medios procesales de defensa que le otorga el ordenamiento jurídico interno, entre los que se halla la presentación de los recursos pertinentes, no signifique un comportamiento del recurrente contrario al desarrollo del proceso dentro del "plazo razonable», aun cuando ello haya supuesto una demora temporal del litigio ${ }^{17}$.

3..$^{\circ}$ En relación con el comportamiento de las autoridades nacionales, el TEDH ha reconocido que incumbe a los Estados organizar el sistema judicial de tal manera que los órganos judiciales puedan garantizar a todas las personas el derecho a obtener una resolución definitiva sobre sus derechos y obligaciones civiles dentro de un plazo razonable ${ }^{18}$. La conducta de las autoridades estatales en la conducción del proceso ha sido, a juicio del TEDH, criterio determinante de la producción de los retrasos cuando estos se han debido a comportamientos personales de los titulares de los órganos judiciales de los Estados en la dirección procesal de los asuntos (que pueden dar incluso lugar a responsabilidad judicial individual). Pero también lo ha sido cuando las demoras de los procesos tienen su origen en causas estructurales por una organización inadecuada o deficiente del sistema judicial o por una carencia importante de medios materiales o personales, particularmente si para solucio-

12 STEDH König c. Alemania, de 28 de junio de 1978.

13 STEDH Scopelliti c. Italia, de 23 de noviembre de 1993 y Serrano Contreras c. España, de 20 de marzo de 2012.

14 SSTEDH Monnet c. Francia, de 27 de octubre de 1993 y Liga Portuguesa de Futbol Profesional c. Portugal, de 17 de octubre de 2016.

15 SSTEDH Pretto y otros c. Italia, de 8 de diciembre de 1983; Ruiz Mateos c. España, de 23 de junio de 1993 y Gast y Popp c. Alemania, de 25 de febrero de 2000.

16 Actuaciones obstruccionistas o maniobras dilatorias realizadas por el demandante como la solicitud de aplazamientos injustificados de audiencias en determinados procedimientos, SSTEDH Dfehmi Koç c. Turquía, de 27 de junio de 2007 y Laidin c. Francia, de 7 de abril de 2003; los frecuentes cambios de abogados, König c. Alemania, de 28 de junio de 1978; el retraso en la interposición de un recurso de casación varios meses después de anunciar la intención de presentarlo, STEDH Papachelas c. Grecia, de 25 de marzo de 1999; o la interposición de numerosas demandas y recursos con la finalidad de recusar a la mayoría de los magistrados del tribunal, SSTEDH Ringeisen $c$. Austria, de 16 de julio de 1971 y Sürmeli c. Alemania, de 8 de junio de 2006.

17 Cfr., entre otras, las SSTEDH Corigliano c. Italia, de 10 de diciembre de 1982; Guincho c. Portugal, de 10 de julio de 1984; Kalachnikov c. Rusia, de 15 de octubre de 2002; Holomiov c. Moldavia, 7 de febrero de 2007; Salmanovcv. Rusia, de 31 de octubre de 2010 y Süveges c. Hungria, de 2 de mayo de 2016.

18 Por todas, la STEDH Neumeister c. Austria, de 27 de junio de 1968. 
nar estos inconvenientes las autoridades legislativas, administrativas o judiciales del Estado no han adoptado las medidas necesarias. En este sentido, el TEDH ha imputado a las autoridades nacionales los retrasos judiciales de carácter estructural $\mathrm{u}$ organizativo, en supuestos como la existencia de vacantes prolongadas de los titulares de los órganos judiciales, o por cambios frecuentes de sus titulares ${ }^{19}$. El Tribunal ha admitido también la responsabilidad de las autoridades nacionales en retrasos debidos a una paralización injustificada de determinadas actuaciones procesales que, a su vez, pueden coincidir con la sobrecarga de trabajo de algunos órganos judiciales ${ }^{20}$, o a la realización de actuaciones procesales innecesarias ${ }^{21}$.

Uno de los argumentos más utilizados por los Gobiernos de los Estados para justificar los retrasos indebidos denunciados por los recurrentes ante el TEDH es el de la sobrecarga de trabajo de los órganos judiciales ${ }^{22}$. A este respecto, el Tribunal ha establecido una distinción, ya clásica, entre atascos estructurales o crónicos y atascos coyunturales o temporales. El TEDH no admite los primeros como causa justificativa de la extralimitación del «plazo razonable», al entender que el Estado no ha adoptado las medidas necesarias y eficaces para impedirlo ${ }^{23}$. No obstante, en algunos casos, el TEDH ha apreciado (aunque no los ha considerado determinantes para exonerar de responsabilidad a los Estados) que los retrasos y atascos de algunos órganos judiciales se hayan producido a consecuencia de situaciones extraordinarias por las que estaba atravesando el país, como la reunificación alemana ${ }^{24}$, el cambio de un sistema de economía planificada a un sistema de economía de mercado $^{25}$ o la transición de un régimen político comunista, socialista o

19 SSTEDH Deumeland c. Alemania, de 29 de mayo de 1986; Capuano c. Italia, de 25 de junio de 1987; Triggiani c. Italia, de 19 de febrero de 1991; Wiesinger c. Austria, de 30 de octubre de 1991; Debono c. Malta, de 7 de mayo de 2006; Nold c. Alemania, de 11 de diciembre de 2006; Salmanovc c. Rusia, de 31 de octubre de 2010; Grujović c. Serbia, de 21 de octubre de 2010 y Utyuzhnikova c. Rusia, de 7 de enero de 2011.

20 SSTEDH König c. Alemania, de 28 de junio de 1978; Bock. c. Alemania, de 29 de marzo de 1989; Terranova c. Italia, de 4 de diciembre de 1995; Mavronichis c. Chipre, de 24 de abril de 1998; Pélliser y Sassi c. Francia, de 25 de marzo de 1999; Prischl c. Austria, de 26 de julio de 2007; Tomazic c. Eslovenia, de 13 de diciembre de 2008; Filipov v. Bulgaria, 10 de septiembre de 2010; Glykantzi c. Grecia, de 30 de enero de 2013; Stasik. c. Polonia, de 6 de enero de 2016 y Albertina Carvalho e filhos lda c. Portugal, de 4 de julio de 2017.

21 SSTEDH Kemmache c. Francia, de 27 de noviembre de 1991; Vallée c. Francia; de 26 de abril de 1994; Doustaly c. Francia, de 23 de abril de 1998; Ayık c. Turquía, de 21 de enero de 2009; Yardimci c. Turquía, de 28 de junio de 2010 y Makbule Akbaba y otros c. Turquía, de 17 de diciembre de 2012.

22 Argumento «manido», como lo califican Esparza Leibar, I. y Etxxebarría Guridi, J.F., «Art. 6. Derecho a un proceso equitativo». En Lasagabaster Herrarte, I. (dir.), Convenio Europeo de Derechos Humanos. Comentario Sistemático. Civitas-Thomson-Reuters, Madrid, 2015, pp. 274-275.

23 SSTEDH Zimmermann y Steiner c. Suiza, de 13 de julio de 1983; Martins Moreira c. Portugal, de 26 de octubre de 1988; Pizzettic. Italia, de 26 de febrero de 1993; Muti c. Italia, de 23 de marzo de 1994; Caillot c. Francia, de 4 de septiembre de 1999; Lenaertsc. Belgique, de 11 de junio de 2004; Nold c. Alemania, de 11 de diciembre de 2006.

24 Cfr. las SSTEDH Pammel y Probstmeier c. Alemania, ambas de 1 de julio de 1997 (parágrafos 69-71 y 64-66), en las que el TEDH condena al Estado alemán por vulneración del derecho del art. 6.1 CEPDH, al considerar excesiva la duración de un procedimiento constitucional sustanciado ante el Tribunal Constitucional Federal. El TEDH no admite como justificación de la demora (alegada por las autoridades alemanas) la existencia de una sobrecarga crónica del Tribunal Constitucional Federal desde finales de los años setenta, ni tampoco el hecho de que tuviera que juzgar asuntos más urgentes, de considerable importancia en el plano político y social, entre los que se encontraban algunos relativos a las consecuencias de la reunificación alemana. Es más, el TEDH recuerda que es obligación del Estado adoptar las medidas oportunas para que el Tribunal Constitucional alemán cuente con el personal y los medios necesarios para tramitar los procedimientos que ante él se planteen dentro de un «plazo razonable».

25 Vid. la STEDH Podbielski c. Polonia, de 30 de octubre de 1998 (parágrafo 38). 
autoritario a otro democrático ${ }^{26}$. Sin embargo, los segundos, los atascos coyunturales, ocasionales o pasajeros, sí han sido admitidos por el TEDH como elemento justificativo de los retrasos en las causas o pleitos, siempre que se hayan producido de forma imprevista y excepcional y que el Estado haya adoptado medidas adecuadas y suficientes para atajarlos ${ }^{27}$.

$4^{\circ}$ El TEDH, de forma ocasional y según las circunstancias del caso, ha utilizado un cuarto criterio para determinar si la duración de un proceso es o no razonable y si se ha vulnerado o no el derecho del art. 6.1 CEDH. Consiste en el interés relevante que el demandante arriesga en el litigio o las eventuales consecuencias que la demora en la tramitación del proceso puedan causar en la esfera personal, familiar y patrimonial del demandante. Mediante este criterio, el Tribunal insta a las autoridades nacionales a que resuelvan los procesos con diligencia y rapidez por el especial interés que en ellos se dilucida. Se intenta que prioricen la decisión de determinados procesos por el interés que está en juego en el litigio. A este respecto, el TEDH ha valorado, entre otros, la importancia particular de los siguientes intereses que, afectando a la libertad personal, integridad física o mental, o al patrimonio del recurrente, podían verse comprometidos por la excesiva duración del proceso: estar sometido a una situación de prisión provisional o a la imposición de una pena grave ${ }^{28}$; estar afectado por una enfermedad grave o incurable con una esperanza de vida reducida ${ }^{29}$; poner en entredicho la capacidad mental del recurrente ${ }^{30}$; condicionar el ejercicio de una actividad profesional ${ }^{31}$; ser privado de la facultad de disponer del patrimonio, de una renta o de una

26 Cfr., entre otras, la STEDH Guincho c. Portugal, de 10 de julio de 1984 (parágrafos 21, 38 a 40), en la que el TEDH reconoce los esfuerzos realizados por el Gobierno portugués, después de la restauración democrática a partir de 1974, para transformar su sistema judicial, que estaba atravesando una situación problemática como consecuencia del proceso de descolonización y la crisis económica. El Tribunal valora algunas de las medidas adoptadas, en octubre de 1980 y marzo de 1981, para remediar el imprevisible aumento del volumen de litigios, como el nombramiento de jueces con poca experiencia al frente de tribunales sobrecargados. Sin embargo, las considera insuficientes y tardías ante la dimensión estructural que había adquirido el colapso de los tribunales, condenando al Estado portugués por violación del art. 6.1 CEDH. También lo hace con el Estado español en la STEDH Unión Alimentaria Sanders, S.A. c. España, de 7 de julio de 1989 (parágrafos 38 a 41), a la que nos referiremos de forma detallada más adelante.

27 Vid. las SSTEDH Buchbolz c. Alemania, de 6 de mayo de 1981; Zimmermann y Steiner c. Suiza, de 13 de julio de 1983; Pammel c. Alemania, de 1 de julio de 1997; Trickovic c. Slovénia, de 27 de marzo de 2002; Hadjikostova c. Bulgaria, de 4 de marzo de 2004 y Tsoukalas c. Grecia, de 22 de octubre de 2010. En las SSTEDH Trickovic c. Slovénia, de 27 de marzo de 2002 y Hadjikostova c. Bulgaria, de 4 de marzo de 2004, el TEDH considera que no se ha vulnerado el art. 6.1 CEDH, a pesar de que los retrasos y sobrecarga de trabajo que padecen algunos órganos judiciales se ha debido a las reformas procesales y de organización judicial realizadas durante los años de transición política de un sistema socialista a uno democrático. El TEDH, sin embargo, valora positivamente las medidas correctivas adoptadas por el Gobierno y por el Tribunal Constitucional eslovenos para reducir la sobrecarga de trabajo que sufrió la Corte Constitucional eslovena (STEDH Trickovic c. Slovénia, de 27 de marzo de 2002, parágrafos 67 y 68); o las acometidas por el Gobierno búlgaro para agilizar la tramitación de los procesos en órganos judiciales que se encontraban colapsados (STEDH Hadjikostova c. Bulgaria, de 4 de marzo de 2004, parágrafo 31).

28 SSTEDH Neumeister c. Austria, de 27 de junio de 1968; Abdoella c. Países Bajos, de 25 de noviembre de 1992; Soto Sánchez c. España, de 25 de febrero de 2004; Cabala c. Eslovaquia, de 6 de diciembre de 2007; Filipov c. Bulgaria, 10 de septiembre de 2010 y Süveges c. Hungria, de 2 de mayo de 2016.

29 SSTEDH Vallée c. Francia, de 26 de abril de 1994; A. y otros c. Dinamarca, 8 de febrero de 1996; Holomiov c. Moldavia, 7 de febrero de 2007 y Oyal c. Turquía, de 23 de junio de 2010.

30 STEDH Bock. c. Alemania, de 29 de marzo de 1989.

31 SSTEDH Doustaly c. Francia, de 23 de abril de 1998 y Rumpf c. Alemania, de 2 de diciembre de 2010. 
compensación económica $^{32}$; o del acceso a prestaciones de asistencia social ${ }^{33}$; o a una determinada pensión ${ }^{34}$; o a una indemnización como víctima de un accidente de circulación ${ }^{35}$; o a un fondo de pensiones por un accidente de trabajo ${ }^{36}$.

5. En el ámbito de la jurisdicción constitucional, el TEDH, para declarar si se ha conculcado o no el derecho del art. 6.1 CEDH, además de valerse de los criterios anteriores, ha tenido en cuenta otros factores como la naturaleza e importancia político y social de los asuntos de que conozcan, o el principio de «una buena administración de justicia» ${ }^{37}$. Así se pone de manifiesto, por ejemplo, en la STEDH Leela Förderkreis E.V. and Others c. Alemania, de 6 de febrero de 2009, cuando se afirma que, aunque la obligación del art. 6.1 CEDH de que los casos sean juzgados en un plazo razonable «se aplique también a la Corte Constitucional, no puede construirse de la misma forma que para los tribunales ordinarios. La función del Tribunal Constitucional como guardián de la Constitución hace que, en ocasiones, se tengan en cuenta otros factores distintos al mero orden cronológico en que se registran los casos, como el de la naturaleza del asunto y su importancia en términos políticos y sociales» (parágrafo 63$)^{38}$.

\section{LAS CONDENAS A ESPAÑA POR LA VIOLACIÓN DEL DERECHO A SER JUZGADO EN UN PLAZO RAZONABLE}

\section{La aplicación del art. 6.1 CEDH a todos los órdenes jurisdiccionales, incluida la jurisdicción constitucional}

El TEDH ha condenado a España en dieciséis ocasiones ${ }^{39}$ por la vulneración del derecho a un juicio en un plazo razonable. Del examen de la jurisprudencia del Tribunal

32 SSTEDH Buchbolz c. Alemania, de 6 de mayo de 1981 y Hadjikostova c. Bulgaria, de 4 de marzo de 2004.

33 STEDH Salesi c. Italia, de 26 de febrero de 1993.

34 SSTEDH Nibbio, Borgese, Biondi, Monaco y Lestini c. Italia, de 26 de febrero de 1992; Sürmeli c. Alemania, de 8 de junio de 2006 y Tsoukalas c. Grecia, de 22 de octubre de 2010.

35 STEDH Silva Pontes c. Portugal, de 23 de marzo de 1994.

36 STEDH Nunes Violante c. Portugal, de 8 de septiembre de 1999.

37 Elementos que en la STEDH Süsmann c. Alemania, de 16 de septiembre de 1996, son determinantes para que el TEDH declare que no existió vulneración del art. 6.1 CEDH (parágrafos 57 a 60).

38 De ahí que este sea también un argumento esgrimido por los Gobiernos de los Estados para justificar los retrasos de algunos procesos constitucionales. Cfr. en este sentido, la STEDH Süsmann c. Alemania, de 16 de septiembre de 1996, en la que, ante la alegación del Gobierno alemán de que el Tribunal Constitucional Federal tiene como función garantizar el respeto de un derecho fundamental «objetivo» y no decidir sobre derechos y obligaciones civiles de los particulares, el TEDH afirma expresamente que «no desconoce en absoluto la función y estatuto particulares de un Tribunal Constitucional, cuya misión es vigilar el respeto a la Constitución por parte de los poderes legislativo, ejecutivo y judicial y que, en aquellos Estados que han previsto el derecho a un recurso individual, asegura a los ciudadanos una protección jurídica adicional en el nivel nacional de los derechos fundamentales garantizados en la Constitución» (parágrafo 37). Vid. también la STEDH Probstmeier c Alemania, de 1 de julio de 1997 (parágrafo 44).

39 La primera en el año 1989, STEDH Unión Alimentaria Sanders, S.A. c. España, de 7 de julio; otra en 1993 , STEDH Ruiz Mateos c. España, de 23 de junio; otra en 2002, STEDH Díaz Aparicio c. España, de 11 de enero; cuatro en 2004, SSTEDH González Doria Durán de Quiroga c. España y López Sole y Martín de Vargas c. España, ambas de 28 de enero; Soto Sánchez c. España, de 25 de febrero y Quiles González c. España, de 27 de abril; otra en 2005, Alberto Sánchez c. España, de 16 de febrero; tres en 2009, SSTEDH Iribarren Pinillos c. España, de 8 de abril y Moreno Carmona c. 
puede comprobarse cómo el Estado español ha incumplido el derecho del art. 6.1 CEDH por los retrasos excesivos en la tramitación de causas seguidas ante órganos judiciales de todos los ordenes jurisdiccionales (salvo el militar) y en cualquiera de las fases en que se encontrara el proceso. Así, pueden citarse, por ejemplo, en el orden civil, la STEDH Ortuño Ortuño c. España, de 27 de septiembre de 2011, dictada en ejecución de una sentencia firme en un procedimiento de liquidación del régimen de gananciales, cuya duración supera los once años en una sola instancia.

En el orden penal, la STEDH Menéndez García y Álvarez González c. España, de 15 de marzo de 2016, considera que no cumple con las exigencias del «plazo razonable» la instrucción de un proceso penal cuya duración ha sido de cuatro años; o que un procedimiento se haya quedado en la fase instructora, habiendo durado trece años y medio cuando se dicta el auto de sobreseimiento definitivo por haber prescrito el delito (STEDH Moreno Carmona c. España, de 9 de junio de 2009); o que en un procedimiento de ejecución de una sentencia penal se haya invertido un lapso de tiempo de más de siete años y nueve meses (STEDH, Bendayan Azcantot y Benalal Bendayan c. España, de 9 de junio de $2009^{40}$ ).

En el orden contencioso-administrativo, el TEDH ha declarado que contradice también la obligación del "plazo razonable» la duración de más de cinco años y cuatro meses de un incidente sobre la competencia de un tribunal (STEDH Alberto Sánchez c. España, de 16 de febrero de 2005); o que el procedimiento en una única instancia jurisdiccional dure diez años (STEDH Comunidad de Propietarios Pando n. $20 v$ España, de 20 de diciembre de 2016), o diecinueve años en cuatro instancias jurisdiccionales, con una suspensión en una de ellas de casi seis años (STEDH Ruiz-Villar Ruiz c. España, de 20 de diciembre de 2016).

En el orden social se ha planteado también ante el TEDH alguna demanda por la duración excesiva de un proceso laboral, aunque el Tribunal la ha inadmitido por no haberse agotado todos los recursos del Derecho interno, concretamente el previsto en el art. 292 y ss. LOPJ para reclamar ante el Ministerio de Justicia la responsabilidad patrimonial por el funcionamiento anormal de la Administración de Justicia por la presunta dilación indebida (Decisión del TEDH Balsells i Castelltort y otros c. España, de 6 de enero de 2015).

En el ámbito de la jurisdicción constitucional, el TEDH ha condenado también a España por infracción del derecho a un juicio en un plazo razonable cuando, por ejemplo, el periodo de duración de dos cuestiones de inconstitucionalidad ha sido de siete años y nueve meses (STEDH Ruiz Mateos c. España, de 23 de junio de 1993); o cuando el tiempo invertido en la tramitación de un recurso de amparo ha sido de tres años y dos meses (STEDH Díaz Aparicio c. España, de 11 de enero de 2002) o de

España y Bendayan Azcantot y Benalal Bendayan c. España, ambas de 9 de junio; otra en 2011, STEDH Ortuño Ortuño c. España, de 27 de septiembre; otra en 2012, STEDH Serrano Contreras c. España, de 20 de marzo y tres en 2016, SSTEDH Menéndez García y Álvarez González c. España, de 15 de marzo y Ruiz-Villar Ruiz c. España y Comunidad de Propietarios Pando n. 20 c. España, ambas de 20 de diciembre.

40 En esta sentencia, que trata de la ejecución de un fallo que impone a un particular la obligación de abonar los daños y perjuicios por la responsabilidad civil resultante de una infracción penal, el TEDH afirma claramente, en el parágrafo 66, que el art. 6.1 CEDH «exige que todas las fases de los procesos judiciales que tienden a resolver las «impugnaciones sobre derechos y obligaciones de carácter civil» concluyan en un "plazo razonable», sin que puedan exceptuarse las fases posteriores a las resoluciones dictadas sobre el fondo. Por tanto, la ejecución de una sentencia de cualquier jurisdicción debe ser considerada parte integrante del «juicio» según el artículo 6 (sentencia Hornsby c. Grecia, 19 de marzo de 1997)». 
cinco años y cinco meses (STEDH Soto Sánchez c. España, de 25 de febrero de 2004); o cuando en la admisión de un recurso de amparo se ha tardado ocho meses (STEDH Quiles González c. España, de 27 de abril de 2004) u once meses (SSTEDH González Doria Durán de Quiroga c. España y López Sole y Martín de Vargas c. España, ambas de 28 de enero de 2004).

Actualmente, es doctrina consolidada del TEDH la aplicación del derecho del art. 6.1 CEDH al ámbito de la jurisdicción constitucional ${ }^{41}$, como puede verse en una de sus últimas decisiones sobre esta materia, la STEDH Cicmanec c. Eslovaquia, de 28 de septiembre de 2016, en la que el Tribunal condena a Eslovaquia por la vulneración del derecho a ser juzgado en un plazo razonable por la duración excesiva de un proceso civil en cuyo cómputo se ha incluido también el periodo de tiempo transcurrido en la tramitación de los correspondientes recursos presentados ante la Corte Constitucional eslovaca $^{42}$.

El TEDH aplica el derecho a ser juzgado en un plazo razonable del art. 6.1 CEDH a los países que cuentan en su organización institucional con Tribunales Constitucionales, aunque estos no formen parte del poder judicial, como sucede en España. Para determinar la vulneración del derecho del art. 6.1 CEDH, el TEDH puede comprobar la duración del proceso incluyendo en el cómputo total el tiempo transcurrido ante los Tribunales ordinarios y el invertido ante los Tribunales Constitucionales, siempre que el resultado de los procedimientos constitucionales influya sobre el desarrollado ante los tribunales ordinarios. No obstante, en algunos casos, el TEDH ha declarado la violación del derecho del art. 6.1 CEDH por los retrasos producidos única y exclusivamente en los procedimientos tramitados ante las Cortes Constitucionales ${ }^{43}$. Ahora bien, como ya se ha dicho, el TEDH, para controlar la duración de los procesos constitucionales y determinar si se ha lesionado o no el derecho del art. 6.1 CEDH, además de utilizar los clásicos

41 Aunque no ha sido siempre así, según puede constatarse en la STEDH Buchbolz c. Alemania, de 6 de mayo de 1981, en la que el TEDH se mostraba reacio a incluir a los Tribunales Constitucionales en el ámbito de aplicación del derecho del art. 6.1 CEDH (parágrafos 47 y 48). El TEDH da un giro a su jurisprudencia, en la STEDH Deumeland c. Alemania, de 29 de mayo de 1986, al incluir el período de tiempo tramitado ante el Tribunal Constitucional Federal dentro de la totalidad del período objeto de examen por el TEDH para determinar si ha respetado o no el «plazo razonable» del art. 6.1 CEDH, ya que, aunque al Tribunal Constitucional Federal «no le correspondía resolver sobre la cuestión de fondo, su resolución podía afectar al resultado del litigio» (parágrafo 77). Criterio que se reitera, entre otras, en las SSTEDH Bock c. Alemania, de 29 de marzo de 1989; Süsmann c. Alemania, de 16 de septiembre de 1996; Probstmeier c. Alemania, de 1 de julio de 1997; Gast y Popp c. Alemania, de 25 de febrero de 2000; Kirsten c. Alemania, de 9 de julio de 2007 y Leela Förderkreis E.V. and Others c. Alemania, de 6 de febrero de 2009. En esta última sentencia, se examina la duración de unos procedimientos tramitados directamente ante el Tribunal Constitucional Federal, el TEDH considera que el tiempo que dichos procedimientos estuvieron pendientes ante la Corte Constitucional, once años y tres meses, excedió considerablemente del «plazo razonable» (parágrafo 65).

42 El TEDH, citando jurisprudencia anterior, señala que la garantía del «plazo razonable» del art. 6.1 CEDH es aplicable también a los procedimientos que son competencia de las Cortes Constitucionales (parágrafo 70). De acuerdo con las circunstancias del caso y la aplicación de los criterios de la complejidad del litigio, la conducta del demandante y de las autoridades competentes, así como del interés del litigio para el demandante, el TEDH concluye que se ha vulnerado el derecho del art. 6.1 CEDH por una duración excesiva de los procesos entablados (nueve años y once meses) (parágrafos 72 a 74). Cfr. también la STEDH Hajrudinović c. Eslovenia, de 21 de mayo de 2015, en relación con un proceso cuya duración excesiva comprende procedimientos de carácter laboral y constitucional (parágrafos 41 y 42).

43 Cfr. al respecto, las SSTEDH Soto Sánchez c. España, de 25 de febrero de 2004; Leela Förderkreis E.V. and Others c. Alemania, de 6 de febrero de 2009 y Prežec c. Croatia, de 15 de octubre de 2010. 
criterios objetivos ya mencionados anteriormente, ha valorado también, por la función que tienen los Tribunales Constitucionales de guardianes de la Constitución, otros factores como la naturaleza e importancia político-social de los asuntos de que conozcan.

El TEDH ha condenado a España por retrasos indebidos en algunos procesos constitucionales - ya sea en una valoración aislada del periodo de duración del proceso constitucional o junto al de otros procesos judiciales- en las siguientes resoluciones ${ }^{44}$.

En la STEDH Ruiz Mateos c. España, de 23 de junio de 1993, leading case en la materia, respecto de dos cuestiones de inconstitucionalidad planteadas de forma sucesiva por tribunales encargados de resolver un litigio sobre el derecho de propiedad ${ }^{45}$. El Gobierno español alegó que para pronunciarse sobre la cuestión del «plazo razonable» era necesario excluir la duración de los procedimientos ante el Tribunal Constitucional, ya que estos no pueden considerarse como una fase más de la acción civil, dado que la función de esa institución cuando conoce de una cuestión de inconstitucionalidad no es la de resolver un conflicto entre derechos de los particulares, sino la de «depurar» objetivamente el Derecho interno anulando las normas contrarias a la Constitución (parágrafos 32 y 34). Sin embargo, el TEDH, de acuerdo con una jurisprudencia ya consolidada desde la STEDH Deumeland $c$. Alemania, de 29 de mayo de 1986, afirma que para calcular el período de tiempo que debe examinarse, ha de tenerse en cuenta el transcurrido ante el Tribunal Constitucional cuando el resultado del proceso constitucional puede influir en el desenlace del litigio debatido ante los tribunales ordinarios (parágrafo 35 ) $^{46}$. En consecuencia, al existir en el caso concreto un estrecho vínculo entre el proceso constitucional y el civil, el TEDH declara que la duración excesiva de los procedimientos constitucionales (siete años y nueve meses para las dos cuestiones de inconstitucionalidad) constituye una vulneración del derecho a un juicio en un «plazo razonable» del art. 6.1 CEDH (parágrafos 37, 51 y 53$)^{47}$.

En la STEDH Díaz Aparicio c. España, de 11 de enero de 2002, el TEDH, conforme a jurisprudencia anterior, afirma que conviene examinar la duración del conjunto de las instancias jurisdiccionales encausadas, incluida la del Tribunal Constitucional, cuyo procedimiento, un recurso de amparo, ha durado tres años y dos meses que, a juicio del TEDH, es

44 Son casos excepcionales y paradójicos, ya que, precisamente, el órgano al que corresponde constitucionalmente la tutela y reparación del derecho fundamental a un proceso sin dilaciones indebidas en el ámbito de la jurisdicción ordinaria, es el que viola el derecho a ser juzgado dentro de un plazo razonable en un proceso constitucional de amparo. Vid., sobre algunas de estas decisiones, SALAdo OsunA, A. «El «plazo razonable» en la administración de justicia...», ob. cit., pp. 304-305 y 323 y 324 y Cobreros Mendazona, E. «El difícil problema de la responsabilidad patrimonial por funcionamiento anormal del Tribunal Constitucional», Revista Vasca de Administración Pública, núm. 87-88, 2010, pp. 303 y ss. y

45 Un comentario a esta sentencia puede verse en CASTro-Rial GARrone, F., «El derecho a un juicio equitativo (Comentario a la sentencia del TEDH de 23 de junio de 1993, Ruiz Mateos contra España)», Revista de Instituciones Europeas, vol. 21, 1994, pp. 157 y ss. y VIDAL Fueyo, C., «Ruiz Mateos c. España (STEDH de 23 de junio de 1993): las garantías del proceso equitativo ante la jurisdicción constitucional», En Conflicto y diálogo con Europa. Las condenas a España del Tribunal Europeo de Derechos Humanos, R. Alcácer Guirao, M. Beladiez Rojo y J.M. Sánchez Tomás (coord.) Civitas Thomson Reuters, Navarra, 2013, pp. 131 y ss.

46 El Gobierno aludió también a la «naturaleza política del Tribunal Constitucional», al no pertenecer al poder judicial, insistiendo en el carácter específico de su estructura, funcionamiento y competencias. Sin embargo, el TEDH entiende que el argumento no es convincente al haber tenido en cuenta, en más de una ocasión, las fases de un procedimiento desarrollado a titulo incidental ante instituciones políticas u organismos o servicios administrativos (parágrafos 36 y 50).

47 Los procedimientos constitucionales se sustanciaron en un lapso de tiempo excesivamente largo, teniendo en cuenta, además, que la primera cuestión de inconstitucionalidad estuvo inactiva más de veinticinco meses y la segunda casi catorce meses (parágrafo 49). 
un periodo excesivo que no responde a las exigencias del «plazo razonable», infringiendo así el art. 6.1 CEDH (parágrafo 22) ${ }^{48}$.

En las SSTEDH González Doria Durán de Quiroga c. España y López Sole y Martín de Vargas c. España, ambas de 28 de enero de 2004, el TEDH considera que se ha vulnerado el derecho del art. 6.1 CEDH por la excesiva duración de las actuaciones penales que se siguen contra los demandantes ante unos juzgados de instrucción, con la singularidad de que el TEDH incluye en el cómputo total del plazo del proceso el período de tiempo destinado a la admisión del recurso de amparo, once meses (parágrafos 34 y 33 respectivamente) ${ }^{49}$.

En la STEDH Soto Sánchez c. España, de 25 de febrero de 2004, el TEDH entiende que la duración excesiva de un recurso de amparo ante el Tribunal Constitucional (cinco años y cinco meses) ${ }^{50}$, de acuerdo con los criterios fijados por su jurisprudencia, constituye una violación del derecho del art. 6.1 CEDH, sin tener en cuenta la alegación por el Gobierno de la complejidad del procedimiento, al no aportar ningún elemento concreto que justifique dicha duración, a pesar de que el sumario estaba compuesto por 22.000 páginas y que se presentaron numerosos recursos de amparo ante el Tribunal Constitucional (parágrafos 39 y 40$)^{51}$.

\section{Algunas singularidades y conclusiones sobre la aplicación de los criterios fijados por el TEDH en las sentencias condenatorias a España por la vulneración del derecho del art. 6.1 CEDH}

En todos los casos de condena al Estado español, el TEDH ha aplicado, a la luz de las circunstancias del caso concreto, los criterios objetivos fijados en su jurisprudencia ya

48 Aunque, en realidad, la duración total del proceso fue de cinco años y dos meses, comprendiendo tanto el periodo de tiempo que transcurrió ante la instancia penal (la Audiencia Nacional) como el que se desarrolló ante la instancia constitucional (el Tribunal Constitucional). Sin embargo, el TEDH solo toma como referencia para declarar la violación del derecho del art. 6.1 CEDH el periodo sustanciado ante el TC. Por otra parte, el TEDH no tiene en cuenta la alegación del Gobierno español sobre la complejidad del proceso penal. Asimismo, recuerda que «corresponde a los Estados contratantes organizar su sistema judicial de forma que sus órganos judiciales puedan garantizar a todos el derecho a obtener una resolución definitiva en un plazo razonable (parágrafo 23).

49 El mismo criterio de incluir en el cómputo total de la duración excesiva de los procesos (administrativo y jurisdiccional contencioso-administrativo), el período de tiempo destinado a la admisión del recurso de amparo (ocho meses), sin excluir el plazo legal para admitir a trámite la demanda (treinta días), se sigue por el TEDH en la STEDH Quiles González c. España, de 27 de abril de 2004 (parágrafo 22).

50 Para el cómputo del plazo el TEDH toma como inicio del proceso la fecha de presentación por el demandante del recurso de amparo ante el Tribunal Constitucional y como fin el de la fecha en que se dictó la sentencia. El TEDH no descuenta ni tan siquiera el tiempo que razonablemente puede durar la tramitación de un recurso de amparo. Es considerada la primera STEDH que condena a España por la vulneración del derecho del art. 6.1 CEDH por el Tribunal Constitucional en un recurso de amparo, durante el periodo que media entre su presentación y su resolución. Se da también la circunstancia de que el Tribunal Constitucional había otorgado parcialmente el amparo al demandante en la STC 122/2000, de 16 de mayo.

51 Un comentario a esta sentencia puede verse en MARTínez SosPEDra, M. «Dilaciones indebidas, justicia, constitucionalidad y TEDH: La sentencia del TEDH Soto Sánchez c. España de 25 de noviembre de 2003», Revista Europea de Derechos Fundamentales, $\mathrm{n}^{\circ} 2,2003$, pp. 115 y ss., que valora positivamente la no exigencia por el TEDH del recurso previsto en los arts. 292 y ss. LOPJ, a los efectos de considerar agotados los recursos del Derecho interno para admitir la demanda ante el TEDH por dilaciones en los procesos constitucionales de amparo, ya que solo una minoría de los amparos se resolvían por resolución motivada y ORTEGA CARBALlo, C.: «Soto Sánchez c. España...», ob. cit., pp. 223 y ss. 
consolidada: la complejidad del asunto; el comportamiento del demandante; la conducta de las autoridades competentes y, ocasionalmente, los intereses que el demandante arriesga en el litigio. A continuación exponemos algunas consideraciones sobre cómo ha aplicado el TEDH estos criterios para deducir de dicha aplicación algunas conclusiones.

a) En relación con el criterio de la complejidad del asunto, este se ha invocado por el Gobierno en varios asuntos como Ruiz Mateos c. España, de 23 de junio de 1993, en el que el Gobierno afirma que la gran complejidad del caso no debe confundirse con la sencillez del procedimiento y que el asunto examinado era complejo no sólo por la amplitud del expediente — alrededor de tres mil páginas-, sino también por la gravedad de los novedosos problemas jurídicos que habían de resolverse. El TEDH admite igualmente que la acción civil principal no era al principio compleja, pero que posteriormente planteó cuestiones constitucionales de innegable dificultad. Sin embargo, en opinión del Tribunal, esta complejidad no justifica de ningún modo la duración excesiva de los procedimientos constitucionales, siete años y nueve meses.

En la STEDH Soto Sánchez c. España, de 25 de febrero de 2004, el Gobierno alega también la complejidad del proceso al tener por objeto un delito de tráfico de drogas con una dimensión internacional («operación Nécora»), en el que intervinieron cincuenta y cuatro acusados, con un expediente de instrucción compuesto de 22.000 páginas y con la presentación de numerosos recursos de amparo ante el Tribunal Constitucional. Factores que, sin embargo, el TEDH no considera suficientes para acreditar la duración excesiva del proceso constitucional, cinco años y cinco meses ${ }^{52}$.

En la STEDH Menéndez García y Álvarez González c. España, de 15 de marzo de 2016, el TEDH manifiesta que el caso era bastante complejo ya que en los procesos penales por la presunta comisión de delitos de fraude y falsedad documental intervenían tres demandantes y diez demandados. Sin embargo, el Tribunal considera que esta circunstancia, en el presente caso, no entraña problemas o dificultades excepcionales para la excesiva duración de la fase instructora, cuatro años.

En la STEDH Serrano Contreras c. España, de 20 de marzo de 2012, el TEDH admite también que el asunto tenía cierta complejidad, entre otras razones, por el número de documentos que debían examinarse, por la implicación de varios acusados y por la tramitación de dos comisiones rogatorias dirigidas a las autoridades italianas. Sin embargo, el TEDH reconoce que esa complejidad tampoco es suficiente para explicar una duración del proceso de once años y un mes.

52 Por el contrario, en la Decisión del TEDH Cándido González Martín y Plasencia Santos c. España, de 15 de marzo de 2016, el TEDH no llega a la misma conclusión, a pesar de estar ante una instrucción de un proceso penal que denotaba cierta complejidad por el asunto, el enjuiciamiento de varios delitos de prevaricación, malversación de caudales públicos, cohecho y blanqueo de capitales, por el número de personas afectadas, con la recusación del magistrado encargado inicialmente de la instrucción y la presencia de un aforado entre los inculpados y por un expediente de instrucción compuesto de 2.000 páginas, con dos anexos de más de 5.000 páginas. Sin embargo, el TEDH inadmite la demanda por considerar justificado el periodo de tiempo en que se mantuvo secreto el sumario, un año para unos delitos y cuatro años y tres meses para otros. En opinión del Tribunal, el mantenimiento del secreto del sumario por tan largo periodo de tiempo era necesario para evitar interferencias o actuaciones que pusieran en peligro el éxito de la investigación. 
En la STEDH Alberto Sánchez c. España, de 16 de febrero de 2005, en que se alega que la instrucción del expediente administrativo es compleja por el número de personas que en él han intervenido, hecho que no es apreciado por el Tribunal que, además, reconoce la falta de diligencia de la Administración en el asunto al haber tardado en enviar el expediente administrativo a la Audiencia Nacional cuatro años y seis meses después de peticiones reiteradas.

En la STEDH Ruiz-Villar Ruiz c. España, de 20 de diciembre de 2016, en la que el Gobierno y el TEDH aprecian la complejidad del procedimiento por la naturaleza del asunto examinado, la delimitación del dominio público hidráulico, por el número elevado de partes involucradas, por la necesidad de solicitar varios dictámenes técnicos y por lo voluminoso del expediente. Sin embargo, el TEDH entiende que, a pesar de dichas circunstancias, no puede justificarse una duración del proceso de diecinueve años, al igual que no lo admitió en otros casos anteriores sobre un asunto similar, las concentraciones parcelarias (Walder c. Austria, de 30 de enero de 2001 y Klug c. Austria, de 15 de enero de 2009), cuyos procesos duraron, respectivamente, veintidós y veinte años, en los que se declaró también la vulneración del art. 6.1 CEDH.

En la STEDH Iribarren Pinillos c. España, de 8 de abril de 2009, en la que el TEDH admite también que el asunto revestía cierta complejidad, particularmente el procedimiento penal dirigido a la identificación de los culpables del delito de lesiones previo y necesario para acudir al procedimiento administrativo de reclamación de responsabilidad patrimonial al Estado. Sin embargo, en opinión del TEDH, esta circunstancia no justifica una duración total del proceso de once años y diez meses, aunque, como ingenuamente aduce el Gobierno, haya intervenido en la causa el Tribunal Supremo.

b) En lo que concierne al comportamiento del demandante, en la STEDH Unión Alimentaria Sanders, S.A. c. España, de 7 de julio de 1989 (parágrafo 35), el TEDH, de acuerdo con la Comisión, considera que la conducta concreta de la sociedad demandante de no presentar un segundo recurso de amparo después del fracaso del primero, «fue conforme con la obligación que tiene todo recurrente de realizar con diligencia los actos que le correspondan, de abstenerse de actuaciones dilatorias y de aprovechar las posibilidades que le ofrezca el Derecho interno para abreviar el procedimiento».

En la STEDH Ruiz Mateos c. España, de 23 de junio de 1993 (parágrafos 42-43 y 59), el Gobierno reprocha a los demandantes una actitud dirigida a dilatar la duración del procedimiento civil, al ejercitar de forma abusiva una acción restitutoria en relación con una expropiación realizada mediante una ley. Con dicha acción se inducía a los tribunales competentes a que plantearan una cuestión de inconstitucionalidad, retrasando considerablemente el desarrollo del proceso en todas las instancias. El TEDH, sin embargo, no comparte esta tesis al considerar que los actores utilizaron el único medio - la cuestión de inconstitucionalidad-que les ofrecía la legislación española para defender sus intereses, el derecho de propiedad, dado que no podían presentar un recurso de amparo al regularse ese derecho en el art. $33 \mathrm{CE}$, fuera de los preceptos constitucionales tutelables mediante el amparo constitucional. 
En la STEDH Moreno Carmona c. España, de 9 de junio de 2009 (parágrafos 33 a 36 y 50 a 54), se alega por el Gobierno que el demandante contribuyó a la duración excesiva del proceso al no haber solicitado al Juez de Instrucción la agilización del proceso penal incoado contra él, beneficiándose posteriormente de la prescripción del delito por la inacción de la jurisdicción penal. El TEDH considera que, aunque el demandante no ha intentado agilizar el proceso, no parece haber contribuido a su duración excesiva, ya que puede constatarse, además, que acudió — sin éxito_ - a la vía indemnizatoria prevista en el art. 292 y ss. LOPJ para reclamar una indemnización por los daños causados por las dilaciones. De ahí que sea excesivo exigir al demandante que entable la acción mencionada por el Gobierno, cuando ha utilizado «otra vía de recurso eficaz y suficiente que tiene prácticamente el mismo fin (Decisión Günaydin c. Turquía, de 25 de abril de 2002)» ${ }^{53}$. En conclusión, a juicio del TEDH, no puede atribuirse al demandante responsabilidad alguna en la demora del proceso por no haber agilizado su tramitación cuando el procedimiento penal se quedó en la fase de instrucción y esta llegó a durar trece años y seis meses hasta que finalmente se dictó el auto de sobreseimiento definitivo por haber prescrito el delito.

En la STEDH Ortuño Ortuño c. España, de 27 de septiembre de 2011 (parágrafos 54 y 62), el Gobierno manifiesta que el retraso del proceso se explica en parte por el comportamiento de la demandante, ya que en el procedimiento de ejecución de la sentencia presentó denuncias contra algunos de sus abogados de oficio, que renunciaron a representarla por la falta de confianza en su trabajo y contra algunos jueces de primera instancia por abuso de poder y también contra tres magistrados del Tribunal Constitucional. El TEDH admite que son circunstancias que contribuyeron a la prolongación en el tiempo del proceso; sin embargo, considera que responden también a la utilización por la demandante de todas las vías procesales que le ofrece el ordenamiento para defender sus intereses, actitud que no merece reproche alguno.

En la STEDH Ruiz-Villar Ruiz c. España, de 20 de diciembre de 2016 (parágrafos 20 y 21), el Gobierno afirmó que la duración del procedimiento se debió, entre otros motivos, al comportamiento de algunos de los demandados que habían sobreexplotado el acuífero y entorpecido la labor de varios peritos que debían de emitir un dictamen. Sin embargo, el TEDH reconoce que la duración excesiva del proceso, diecinueve años con largos periodos de inactividad procesal, no podía atribuirse al demandante ni a ninguna de las partes, al menos no se ha podido probar de forma suficiente por el Gobierno.

c) Por lo que se refiere a la conducta de las autoridades nacionales, en la STEDH Unión Alimentaria Sanders, S.A. c. España, de 7 de julio de 1989 (parágrafos 38 a 41), el TEDH, aun teniendo en cuenta las dificultades surgidas como consecuencia de la transición política y las medidas adoptadas por las autoridades nacionales, considera que estas no fueron suficientes para solucionar el problema de la sobrecarga de trabajo que afectaba a algunos tribunales de Barcelona. Estos habían incrementado considerablemente el número de litigios, no sólo por las

53 Cfr. en el mismo sentido, la STEDH Ruiz-Villar Ruiz c. España, de 20 de diciembre de 2016 (parágrafos 13 a 15$)$ 
leyes aprobadas después de la Constitución española, sino también por el aumento de habitantes que por la emigración experimentaron algunas de las provincias catalanas. Con ocasión de los atascos que aquejaban a algunos órganos judiciales de Barcelona, el TEDH reconoce que «un atasco temporal de un tribunal no implica la responsabilidad internacional de un Estado si adopta, con la debida rapidez, las medidas adecuadas para remediarlo», como puede ser «establecer con carácter provisional un determinado orden de preferencia en el despacho de los asuntos, teniendo en cuenta su urgencia y su importancia». Ahora bien, si estas medidas son insuficientes y las situaciones de atasco temporal de los asuntos se convierten en habituales durante varios años (estructurales u organizativas), el TEDH entiende que esta situación no justifica la excesiva duración de los procedimientos, privándose a la sociedad demandante de su derecho a que su causa sea oída dentro de un plazo razonable ${ }^{54}$.

En la STEDH Serrano Contreras c. España, de 20 de marzo de 2012 (parágrafos 57 y 58), frente a los argumentos formulados por el órgano judicial para justificar el retraso en dictar sentencia, concretamente la sobrecarga de trabajo, el TEDH recuerda que, según reiterada jurisprudencia, «el atasco crónico en los asuntos atribuidos a un tribunal no es una explicación válida (Probstmeier c. Alemania, de 1 de julio de 1997)» y no justifica una duración del procedimiento de más de once años para los tres grados o instancias jurisdiccionales. De ahí que con «la exigencia del respeto al «plazo razonable», la Convención subraye la importancia de garantizar que la justicia no se administre con demoras que comprometan su eficacia y credibilidad».

En la STEDH Quiles González c. España, de 27 de julio de 2004 (parágrafos 27 y 28), el TEDH condena a España por violación del art. 6.1 CEDH, por una duración excesiva de un proceso, al apreciar un periodo de inactividad de casi cuatro años en la tramitación de un recurso de apelación ante un Tribunal Superior de Justicia. El TEDH no admite como causas justificativas del retraso la complejidad del asunto ni la alegación por el Gobierno de una sobrecarga de trabajo del tribunal, al haber estado colapsado temporalmente por ingresar 2.390 recursos en un mes. El Tribunal recuerda, por el contario, que es responsabilidad de los Estados «organizar el sistema judicial de tal manera que los órganos judiciales puedan garantizar a todas las personas el derecho a obtener una resolución definitiva sobre sus derechos y obligaciones civiles dentro de un plazo razonable».

d) Por lo que respecta a los intereses arriesgados por el demandante en el litigio, exponemos seguidamente algunos de los que el TEDH ha valorado en las sentencias condenatorias contra España, cuando en ellas se ha mencionado expresamente este criterio para reconocer que los procesos podían haberse tramitado con mayor diligencia y celeridad. Así sucede con la privación de libertad como

54 En esta tesis se apoya también el TEDH en la STEDH Ruiz Mateos c. España, de 23 de junio de 1993 (parágrafo 48), con cita expresa del caso Unión Alimentaria Sanders, S.A. c. España, de 7 de julio de 1989, para considerar que no es convincente el argumento alegado por el Gobierno sobre la carga de trabajo de la Audiencia Provincial de Madrid, que aumentó todavía más a partir de 1985 al haber reorganizado la L.O.P.J. el sistema judicial español. A pesar de ello, en opinión de Gobierno, las autoridades públicas corrigieron esta situación el 10 de junio de 1988 mediante la dotación de jueces en régimen de provisión temporal. Sin embargo, a juicio del TEDH, las medidas se adoptaron tardíamente para el caso examinado. 
consecuencia de la imposición de determinadas penas de prisión. A él se refiere la STEDH Soto Sánchez c. España, de 25 de febrero de 2004, en la que el demandante había sido condenado a una pena de cuatro años y dos meses de prisión menor, impuesta por la Audiencia Nacional, que posteriormente fue aumentada a nueve años de prisión mayor por el Tribunal Supremo. Otro interés arriesgado por el demandante en el proceso ha sido el patrimonio empresarial ante una expropiación por un decreto-ley, STEDH Ruiz Mateos c. España, de 23 de junio de 1993 , en la que se indica expresamente (parágrafo 52), que lo que «se encontraba en juego en este caso era sumamente importante, no sólo para los actores, sino también para la sociedad española en general, debido a la enorme incidencia social y política del mismo: el gran número de personas implicadas —asalariados, accionistas y terceros- y el volumen de los capitales afectados». También han sido considerados como intereses arriesgados por el demandante en el proceso las funciones que legalmente corresponde ejercer a los funcionarios de un determinado cuerpo de la Administración de Justicia, STEDH Alberto Sánchez c. España, de 16 de febrero de 2005; o la valoración de los bienes e intereses que integran una comunidad de gananciales, por falta de acuerdo entre las partes, tras la liquidación del régimen económico matrimonial, SSTEDH Bendayan Azcantot y Benalal Bendayan c. España, de 9 de junio de 2009 y Ortuño Ortuño c. España, de 27 de septiembre de 2011.

Algunas de las conclusiones que pueden deducirse de la aplicación de los criterios anteriores por el TEDH en las sentencias condenatorias contra España son las siguientes.

1. ${ }^{\text {a }}$ En la mayoría de las resoluciones examinadas, aunque se ha alegado por el Gobierno la complejidad del proceso como causa justificante de los retrasos judiciales indebidos, el TEDH no lo ha considerado determinante para excluir la responsabilidad del Estado. A pesar, incluso, de que el propio TEDH haya apreciado en algunos casos cierta complejidad del proceso por lo voluminoso del expediente, por la intervención de numerosas personas (demandantes, acusados y terceros) o por presentar varios recursos y acudir a diversas instancias. Sin embargo, el TEDH no ha estimado suficientes estos factores para acreditar una duración desproporcionada del proceso que, en algún caso, ha sobrepasado los diecinueve años.

2. $\quad$ En algunas sentencias, el Gobierno ha afirmado que la duración excesiva del proceso se ha debido, en parte, a ciertas maniobras dilatorias del demandante (denuncias a sus abogados, jueces, recusaciones...) o, incluso en algún caso, a inacciones procesales. Sin embargo, el TEDH ha reconocido que esas actuaciones son conformes con la obligación de todo recurrente de utilizar diligentemente las vías o recursos que le proporciona el Derecho interno para defender sus intereses.

3. ${ }^{a} \quad$ En todas las sentencias el criterio decisivo y determinante para condenar a España por la duración irrazonable de un proceso ha sido el de la conducta de las autoridades nacionales, particularmente el de las autoridades gubernativas y, en algunos casos, el de las judiciales. Ya sea por la falta de diligencia 
de los titulares de los órganos judiciales en la tramitación de los asuntos o, sobre todo, a problemas estructurales (plazas vacantes en tribunales, necesidad de crear nuevos órganos...), coincidentes, en muchos casos, con la sobrecarga de trabajo de algunos órganos judiciales aquejados de atascos crónicos. Problemas organizativos y atascos crónicos que no han sido admitidos por el TEDH como causa justificativa de los retrasos indebidos, incluso en momentos complicados para el sistema judicial español como en la época de la transición política o con ocasión de algunas decisivas reformas legislativas de carácter procesal.

4. ${ }^{a} \quad$ En algunas resoluciones condenatorias se mencionan determinados intereses que el demandante arriesga en el proceso. Se trata de intereses relacionados con su libertad personal, patrimonio o actividad profesional. Aunque la tutela de estos intereses debiera acelerar la tramitación de los procesos, cuando no ha sido así y se han producido retrasos indebidos en la causa, el TEDH ha valorado este criterio pero no lo ha utilizado como ratio decidendi de las sentencias.

\section{SOBRE MEDIDAS Y REMEDIOS QUE EVITEN FUTURAS CONDENAS AL ESTADO ESPAÑOL POR LA VULNERACIÓN DEL DERECHO A SER JUZGADO EN UN PLAZO RAZONABLE}

No existe en nuestro ordenamiento una medida que a modo de «bálsamo de Fierabrás», de poción mágica, sea capaz de curar totalmente uno de los males y dolencias que aquejan a nuestro sistema judicial, el de las dilaciones indebidas, sobre todo cuando estas tienen un origen estructural.

No obstante, sí se han establecido a lo largo de estos años, por influencia en algunos casos de la jurisprudencia del TEDH, algunas medidas preventivas destinadas a acelerar los procedimientos y a corregir los retrasos ocasionales de los tribunales como consecuencia de una acumulación de asuntos, de ausencias del titular del órgano judicial o de la existencia de vacantes por cualesquiera circunstancias. Para acometer estos inconvenientes y evitar que los retrasos coyunturales puedan convertirse en estructurales, la LOPJ prevé, a lo largo de su articulado, diferentes medidas como el nombramiento de magistrados suplentes para formar Sala en órganos colegiados (art. 199 y ss. LOPJ) y de jueces sustitutos en órganos unipersonales (art. 207 y ss. LOPJ) y, sobre todo, las medidas excepcionales de apoyo y refuerzo judicial a través de los jueces de adscripción territorial (art. 347 bis LOPJ) o de los jueces en régimen de provisión temporal (art. 428 LOPJ).

Son medidas que si se adoptan con rapidez pueden ser útiles, en un primer momento, para solucionar los atascos y retrasos temporales de los órganos judiciales. Se han aplicado, por ejemplo, en situaciones de colapso de los Juzgados de lo Mercantil cuando se han visto desbordados por el ingente número de asuntos que se habían registrado en materia de concursos durante los años críticos de la crisis económica o por el aluvión de demandas que han entrado durante el año 2017 en los Juzgados de Primera Instancia en materia de cláusulas abusivas de los préstamos hipotecarios ( «las cláusulas suelo»). Estas situaciones han dado lugar también a la adopción de otras medidas de carácter organizativo por el Consejo General del Poder Judicial como la transformación 
de los Juzgados de lo Mercantil en tribunales de instancia especializados por materias: patentes, conflictos societarios y defensa de la competencia ${ }^{55}$ o la conversión de determinados Juzgados de Primera Instancia en juzgados especializados para conocer de forma exclusiva, aunque no excluyente de las demandas sobre las «cláusulas suelo» ${ }^{56}$. Ahora bien, cuando no es posible solventar el colapso temporal de los órganos judiciales y este pasa a ser permanente o estructural, la única solución es la creación de nuevos tribunales y la dotación de medios materiales y personales para que estos ejerzan sus funciones de modo efectivo ${ }^{57}$.

55 Cfr. el artículo publicado por SÁnchez, L., «Llegan los Tribunales de lo Mercantil en Instancia como remedio para luchar contra el colapso judicial», disponible en la página web lawEtrends: http://www.lawandtrends. com/, en el que se expone cómo esta medida se aplicó como plan piloto a los Juzgados de lo Mercantil de Barcelona hace dos años, donde ha funcionado con notables resultados y en 2016 la Comisión Permanente del CGPJ la ha aprobado para Sevilla. Así se recoge también en la página web del CGPJ, cuando establece que la Comisión Permanente del CGPJ ha aprobado el día 4 de febrero de 2016 el plan piloto de Tribunal de Instancia Mercantil de Sevilla, conforme al cual se organizan en dos secciones los cinco jueces que actualmente prestan servicio en los Juzgados de lo Mercantil, que debatirán de forma colegiada los asuntos de especial complejidad.

56 Mediante esta medida adoptada por el CGPJ el 1 de junio de 2017, se crearon cincuenta y cuatro juzgados uniprovinciales especializados en esta materia. Sin embargo, como pusieron de manifiesto los Jueces Decanos la medida no estaba produciendo el efecto deseado, pues a finales de octubre de 2017 los juzgados especializados en las cláusulas hipotecarias estaban colapsadas al haber recibido más de 98.600 demandas (que ascendieron a 156,852, a finales de diciembre, según la página WEB de Consejo General del Poder Judicial (CGPJ). Por este motivo, los Jueces Decanos propusieron al CGPJ, al no haberse dotado a los juzgados especializados de todos los medios que precisaban, que los asuntos ingresaron por esta materia a partir del 1 de enero de 2018 pasen a reparto general entre todos los Juzgados de Primera Instancia de todos los partidos judiciales. A este respecto, el Consejo General de la Abogacía Española presentó en junio de 2017, ante la Sala de lo Contencioso-Administrativo del Tribunal Supremo, un recurso contra el acuerdo de la Comisión Permanente del CGPJ por el que se atribuye a determinados juzgados la competencia exclusiva en materia de cláusulas suelo. El Consejo General de la Abogacía Española entendía que el plan del CGPJ estaba agravando el problema que trataba de solucionar, ya que muchos de los juzgados designados carecían de capacidad para absorber las demandas presentadas, impidiendo a los ciudadanos resolver sus conflictos en un tiempo razonable. Cfr., sobre esta información, la página web de Abogacía Española disponible en: http://www. abogacia.es/2017/10/20/los-jueces-decanos-preven-el-colapso-de-los-juzgados-de-clausulas-suelo-y-piden-su-cierre/ y la página web del CGPJ: http://www.poderjudicial.es/portal/site/cgpj/menuitem.65d2c4456b6ddb628e$635 \mathrm{fc} 1 \mathrm{dc} 432 \mathrm{ea0} /$ ?vgnextoid $=3 \mathrm{f} 5 \mathrm{f} 39 \mathrm{e} 75 \mathrm{c} 19 \mathrm{f} 510 \mathrm{VgnVCM} 1000006 \mathrm{f} 48 \mathrm{ac0aRCRD} \& \mathrm{vgnextchannel}=\mathrm{d} 060 \mathrm{f}-$ 20408619210VgnVCM100000cb34e20aRCRD\&vgnextfmt =default\&vgnextlocale=es_ES. La nueva situación de colapso llevó a la Comisión Permanente del CGPJ a aprobar el día 28 de diciembre de 2017, un nuevo plan de especialización de juzgados en materia de acciones individuales sobre condiciones generales incluidas en los contratos de financiación con garantías reales inmobiliarias cuyo prestatario sea una persona física, que entraba en vigor el 1 de enero, con una vigencia de seis meses. El plan sustituía al que se puso en marcha el pasado 1 de junio y respondía a la evolución que han seguido estos asuntos, que en caso de no atribuirse a órganos especializados supondría una carga inasumible para el resto de los juzgados. El plan obedecía también a la próxima entrada en funcionamiento de 77 juzgados creados y constituidos en 2017 y al análisis de la carga de trabajo de los órganos judiciales especializados, que hasta ahora han conocido de estos asuntos de manera exclusiva y no excluyente. El nuevo plan permitiría, manteniendo la atribución de la atribución de la competencia exclusiva a determinados juzgados, establecen en un caso, también la excluyente en aquellas provincias en las que el impacto de reparto del resto de los asuntos entre los órganos judiciales del orden civil lo permitiera. Otra novedad consistía en que, en algunas provincias, la materia objeto de especialización pasaría a ser asumida por juzgados de nueva creación desde la fecha de su entrada en funcionamiento. Véase la página web del CGPJ, disponible en: http://www.poderjudicial.es/portal/site/cgpj/ menuitem.65d2c4456b6ddb63e635fc1dc43ea0/?vgnextoid $=$.

$57 \mathrm{El}$ art. 216 bis, ap. $6^{\circ}$, LOPJ dispone en este sentido que «Si la causa del retraso tuviera carácter estructural, el CGPJ, junto con la adopción de las referidas medidas provisionales, formulará las oportunas propuestas al Ministerio de Justicia o a las Comunidades Autónomas con competencias en la materia, en orden a la adecuación de la plantilla del juzgado o tribunal afectado o a la corrección de la demarcación o planta que proceda». El Tribunal Constitucional, cuando dicta una sentencia en la que declara la violación del derecho a un proceso público sin dilaciones indebidas del art. 24.2 CE, si las dilaciones indebidas que sufre el proceso fueron provocadas por causas 
Otra medida preventiva de carácter provisional y excepcional para afrontar los posibles retrasos temporales en la decisión de los procesos, aludida también por el TEDH en sus decisiones, es la fijación de un orden de tramitación preferente de los asuntos, basado en su urgencia e importancia, así como en el riesgo que para las partes pueda tener la demora en su resolución. Sin embargo, esta medida de dar prioridad a unos asuntos sobre otros, de anteponer en el tiempo la resolución de unos litigios sobre otros por su relevancia, puede servir para taponar temporalmente algunas vías de agua, pero puede dar lugar a que se abran grietas más grandes con riesgo de hundimiento para el barco. Y es que los ciudadanos que vean que la decisión de los litigios de aquellos que se han quejado del retraso ha sido adelantada respecto de los que no lo han hecho, procederán de igual modo, pudiendo llegar a colapsar nuevamente el órgano judicial ${ }^{58}$.

Cuando se han producido dilaciones indebidas en un proceso y estas se han debido a causas estructurales, esto es, a la falta de dotación de medios materiales y personales para que los tribunales ejerzan sus funciones eficazmente o a deficiencias organizativas del sistema judicial, la única solución posible consiste en la adopción de medidas reparatorias que pueden ser de tipo organizativo o de carácter económico.

Las medidas reparatorias organizativas pueden consistir en la creación de nuevos tribunales con una dotación suficiente de medios materiales y personales para que estos ejerzan sus funciones de modo efectivo. Así lo prevé el art. 216bis, apartado 6. ${ }^{\circ}$ LOPJ, cuando dispone que si la causa del retraso tuviera carácter estructural el Consejo General del Poder Judicial, junto con la adopción de las referidas medidas provisionales, formulará las oportunas propuestas al Ministerio de Justicia o las Comunidades Autónomas con competencias en la materia, en orden a la adecuación de la plantilla del juzgado o tribunal afectado o a la corrección de la demarcación o planta que pueda. Las medidas reparatorias organizativas, por la existencia de retrasos crónicos o estructurales, conllevan a la realización de las oportunas reformas legales de tipo procesal u organizativo. Ya sea para modificar los procedimientos jurisdiccionales existentes o para crear un nuevo orden jurisdiccional o nuevos órganos judiciales especializados en determinados asuntos con una asignación suficiente de medios materiales y personales. Así, cada cierto tiempo, el Gobierno y el Parlamento, previo informe del CGPJ, llevan a cabo modificaciones de las leyes procesales de las diferentes órdenes jurisdiccionales, o de la LOPJ, o de la Ley 38/19988, de 28 de diciembre, de Remarcación y de Planta Judicial. En ellos se indica que una de las finalidades perseguidas con las reformas procedimentales u orgánicas e la de agilizar la justicia para evitar la dilaciones indebidas, pero sin merma de las garantías procesales y de la tutela judicial efectiva reconocida constitucionalmente ${ }^{59}$. Aunque en

estructurales, puede considerar oportuno trasladar la sentencia al CGPJ y al Ministerio de Justicia, a los efectos que procedan. Cfr. las SSTC 153/2005, de 6 de junio, FJ 2 y 129/2016, de 18 de julio de 2016, FJ 4.

58 Borrajo Iniesta, I., «Los derechos a un proceso sin dilaciones indebidas...», ob. cit., pp. 142-143, cita este ejemplo en relación con los recursos de amparo ante el Tribunal Constitucional, indicando que la medida referida puede empeorar la situación, antes que remediarla.

59 Cfr. en este sentido, respecto de algunas de las últimas reformas llevadas a cabo, las Exposiciones de Motivos de la Ley 1/2000, de 7 de enero, de Enjuiciamiento Civil; la Ley 42/2015, de 5 de octubre, de reforma de la Ley 1/2000, de 7 de enero, de Enjuiciamiento Civil, en relación con la implantación de las nuevas tecnologías en la Administración de Justicia; la Ley 41/2015, de 5 de octubre, de modificación de la Ley de Enjuiciamiento Criminal para la agilización de la justicia penal y el fortalecimiento de las garantías procesales; la reforma de la Ley de la Jurisdicción Contencioso-administrativa por la DF $3 .^{a}$ de la L.O. 7/2015, de 21 de julio, por la que se modifica la LOPJ de 1985; la L.O. 7/2015, de 21 de julio, por la que se modifica la LOPJ de 1985. 
las reformas legislativas la última palabra la tienen el Gobierno y el Parlamento, asume también un papel decisivo el Consejo General del Poder Judicial, que es la institución que recibe y canaliza la información sobre las necesidades que tienen los órganos judiciales para ejercer sus funciones de modo eficaz. De ahí que este órgano, en cumplimiento del mandato del art. 563 LOPJ, remita anualmente a las Cortes Generales una Memoria sobre el estado, funcionamiento y actividades del Consejo General del Poder Judicial y de los Juzgados y Tribunales, en la que se incluyen las necesidades existentes en materia de personal, instalaciones y recursos ${ }^{60}$. Asimismo, hay que tener presente que la dotación de los medios materiales y personales a los órganos judiciales es competencia del Ministerio de Justicia y de las Comunidades Autónomas que tienen asumida la competencia en esta materia (art. 216 bis, apartado 6. ${ }^{\circ}$ LOPJ).

Por lo que se refiere a la medida reparatoria de tipo económico cosistente en las indemnizaciones concedidas a las víctimas por los daños y perjuicios causados por las dilaciones indebidas de origen estructural, según se ha examinado, se halla regulada en el art. 292 y ss. de la LOPJ para el ámbito de la jurisdicción ordinaria, con la singularidad prevista en el art. 32.8 LRJSP respecto de la jurisdicción constitucional. Es un remedio de carácter económico y subsidiario establecido para reparar los retrasos judiciales cuando estos no han podido corregirse por otros medios y se han convertido en estructurales ${ }^{61}$. Por regla general, el justiciable afectado ha estado sometido a un largo peregrinaje judicial recorriendo numerosas instancias, incluida la del Tribunal Constitucional, hasta llegar al recurso del art. 292 y ss. LOPJ ante el Ministerio de Justicia, cuya decisión es revisable además ante los tribunales de lo contencioso-administrativo. Finalmente y si aún le quedan fuerzas, una vez agotadas todas las vías de recurso disponibles en nuestro Derecho, el interesado puede acudir al TEDH invocando la vulneración del derecho a un proceso dentro del plazo razonable del art. 6.1 CEDH. Si el TEDH considera que se ha violado este derecho, el Estado español sería condenado al pago de una cuantía económica que normalmente oscila entre los 6.000 y 12.000 euros. Puede ser mucho más económico para el Estado abonar esta cantidad que acometer reformas mucho más costosas en la estructura u organización del sistema judicial.

60 En la Memoria del año 2016, aprobada por el Pleno de 26 de julio de 2017, puede consultarse el apartado de "panorámica de la justicia», que es un informe en el que se analiza la situación de los órganos judiciales sobre los datos facilitados por la estadística judicial, elaborados por la Sección de Estadística del CGPJ. En lo que aquí interesa, en dicho apartado se ofrecen datos por cada uno de los órdenes jurisdiccionales y órganos judiciales de los ingresos de asuntos y de las duraciones medias de los procedimientos, comprobando si han aumentado o disminuido respecto del año anterior y valorando la incidencia o impacto que han tenido las modificaciones o reformas legales que se han realizado en los últimos años (algunas de ellas citadas anteriormente). Cfr. la página web del CGPJ, disponible en: http://www. poderjudicial.es/cgpj/es/Poder-Judicial/Consejo-General-del-Poder-Judicial/Actividad-del-CGPJ/Memorias/ Memoria-anual-2017--correspondiente-al-ejercicio-2016-

61 Puede considerarse también como otra medida reparatoria o compensatoria de las dilaciones indebidas padecidas exclusivamente en el proceso penal, la atenuante de dilaciones indebidas del art. 21.6 del Código Penal, añadida con la reforma de la L.O. 5/2010, de 22 de junio, en el que se establece que es circunstancia atenuante «la dilación extraordinaria e indebida en la tramitación del procedimiento, siempre que no sea atribuible al propio inculpado y que no guarde proporción con la complejidad de la causa». Sobre la aplicación de esta atenuante existe una abundante jurisprudencia. La doctrina penal se ha ocupado también ampliamente de su análisis. Vid., entre otros, DíAz-MAROTO Y Villarejo, J., «La nueva atenuante por dilaciones indebidas en la tramitación del procedimiento», La Ley penal: Revista de Derecho Penal, Procesal y Penitenciario, n. ${ }^{\circ}$ 80, 2011, pp. 45 y ss.; Ramírez OrTiz, J.L., «Derechos fundamentales y derecho penal: La circunstancia atenuante de dilaciones indebidas», Derecho y Proceso Penal, n. ${ }^{\circ} 27,2012$, pp. 1 y ss. y Goyena Huerta, J., «La circunstancia atenuante de dilaciones indebidas», Revista Aranzadi Doctrinal, n. ${ }^{\circ}$ 5, 2015, pp. $37 \mathrm{y}$ ss. 
TITLE: The European Court of Human Rights and the Spain sentences for the violation of the right to be heard within a reasonable time of article 6.1 of the European Convention on Human Rights: the difficulties to achieve an optimal time of the judicial processes

ABSTRACT: The paper analyzes the doctrine established by the European Court of Human Rights on the violation of the right to be tried within a reasonable time of art. 6.1 of the European Convention of Human Rights and its application to the Spanish State in the condemnatory judgments that until now have been pronounced. It also examines and proposes some preventive measures aimed at streamline the process and correcting court delays, as well as other reparations.

RESUMEN: El trabajo analiza la doctrina fijada por el Tribunal Europeo de Derechos Humanos sobre la vulneración del derecho a ser juzgado en un plazo razonable del art. 6.1 del Convenio Europeo de Derechos Humanos y su aplicación al Estado Español en las sentencias condenatorias que hasta abora se han dictado. También se examinan y se proponen algunas medidas preventivas destinadas a acelerar los procedimientos y a corregir los retrasos de los tribunales, así como otras de carácter reparatorio.

KEY WORDS: European Court of Human Rights, the right to be heard within a reasonable time, undue delay, judicial proceedings

PALABRAS CLAVE: Tribunal Europeo de Derechos Humanos, derecho a ser juzgado en un plazo razonable, dilaciones indebidas, procesos judiciales

FECHA DE RECEPCIÓN: 10.04.2018

FECHA DE ACEPTACión: 13.09.2018 